\title{
A retrospective study of cysts in the maxillofacial area
}

\author{
Yeon-Woo Jeong, Byung-Hun Kang, Min-Jung Park, Song-Jay Choi, Hong-Ju Park, Hee-Kyun Oh ${ }^{\dagger}$, Min-Suk Kook ${ }^{\star \dagger}$
}

Department of Oral and Maxillofacial Surgery, School of Dentistry, Chonnam National University, Gwangju, Korea

\begin{abstract}
The purpose of this study was to investigate the prevalence of odontogenic cysts in the oral and maxillofacial area. The subjects of this study were diagnosed and treated for cysts in the jaw at Chonnam National University Hospital from January 2013 to December 2017. Patients' information, including age, types and locations of cysts, history of bone grafting, and types of graft material used were recorded by reviewing medical records, clinical examinations, panoramic radiographs, dental computed tomography findings, and biopsy results. Among all 544 cases, the overall male $(352,64.7 \%)$ to female $(192,35.3 \%)$ ratio was $1.8: 1$. The age of the patients ranged from 6 to 87 years, with $103(18.6 \%)$ in their 40s, $95(17.1 \%)$ in their 20s-30s, and $90(16.2 \%)$ in their 50s. In the histopathological distribution, the most common cyst type was a radicular cyst (47.6\%), while dentigerous cyst (29.4\%) was the second most prevalent. The occurrence of the cysts was highest in the posterior mandibular region (42.6\%) and the anterior maxillary region (39.9\%). Cyst enucleation was the most commonly used treatment option (55.6\%), and autogenous bone was the most frequently used bone graft material. In this study, the prevalence of radicular cysts was higher than that of other types of cyst. The prevalence of cysts was higher in older patients than in younger age groups. Treatment of cysts is based on complete enucleation and requires bone grafting, as necessary.
\end{abstract}

Key Words: Bone grafting, Cyst, Prevalence

(c) This is an open-access article distributed under the terms of the Creative Commons Attribution Non-Commercial License (http://creativecommons.org/licenses/by-nc/4.0) which permits unrestricted noncommercial use, distribution, and reproduction in any medium, provided the original work is properly cited.

\section{INTRODUCTION}

A cyst is one of the most commonly found pathological conditions in the oral and maxillofacial region. A cyst, usually referred to as a follicle, is a cavity surrounded by connective tissue with an epithelial lining surrounded by either soft or hard tissue. Inside the cavity is usually liquid or semi-fluid material. Substances within the cavity cause high osmotic pressure, which leads to growth of the cyst. It is a disease that requires rapid diagnosis and treatment because it may destroy adjacent bone and soft tissue [1].

Cysts of the jaw are not new lesions, with the mandible and maxilla as the most frequent anatomical sites of cysts [2]. In some cases, jaw cysts become very large and their removal results in facial asymmetry, adjacent neurovascular bundle damage, and permanent malfunction of the peripheral nerve function [3,4].

The odontogenic epithelium in the maxilla and mandible can be transformed in a variety of odontogenic cysts [5,6]. Teeth also influence the spread of infection from pulp or

Received August 7, 2019; Accepted August 30, 2019

Corresponding author: Min-Suk Kook, Department of Oral and Maxillofacial Surgery, Dental 4D Institute, School of Dentistry, Chonnam National University, 77 Yongbong-ro, Buk-gu, Gwangju 61186, Korea.

Tel: +82-62-220-5436, Fax: +82-62-220-5437, E-mail: mskook2@gmail.com

${ }^{\dagger}$ These authors contributed equally to this work.

Copyright ๑ 2019, Oral Biology Research Institute 
periodontal tissue to the alveolar bone. As early as 1903 , Oliver extrapolated Sutton's classification of odontomas, wherein cysts were described as variants of odontomes. Inflammation in the upper or lower jaw can be the initiation point of cyst formation in the alveolar process. Formation of a large cystic wall that involves tooth buds, during mixed dentition, can cause the loss of permanent teeth. Elderly patients with large cystic formations in either jaw, in all these condition. Marsupialization is the first option in treatment planning for such cases.

To date, marsupialization and enucleation are the most common treatment options for cystic lesions of the jaw, since they were first introduced by Partsch $[7,8]$. Owing to the advances in radiographic assessments, including 3-dimensional dental computed tomography (CT) and histopathologic evaluation, individualization of each patient's treatment plan is possible.

However, ongoing changes in our understanding of cysts, especially with the advent of new cystic entities and the reclassification of older ones owing to advances in imaging, histopathological evaluation, diagnosis, and treatment of cystic lesions, make periodic updates necessary. Therefore, the treatment blueprint needs to be embellished by various adjunctive procedures as per the individual patient's needs to result in a comprehensive treatment plan. The individualization of treatment plans based on various clinical, radiological and histological variables is especially pertinent in developing countries, where the clinical course of jaw cysts is relatively longer due to poor awareness, difficult access to health care, and often late diagnosis. Thus, the treatment choices are more difficult to make. Therefore, a clinical study of cysts and an inventory of the various factors affecting choice of treatment are relevant.

Cysts of the oral and maxillofacial region can be classified as developmental cysts and inflammatory cysts. This paper will examine odontogenic cysts that make up more than $70 \%$ of developmental cysts. Odontogenic cysts can destroy adjacent tissues, causing absorption or expansion of the jaw, pathological fractures, and facial deformities, which may result in functional or aesthetic defects. Therefore, early diagnosis and treatment of odontogenic cysts is imperative.

For accurate diagnosis and treatment of cysts, using sta- tistical data, such as sex, age, and sites of prevalence, can be helpful. Data can be useful to assess differences in a statistical study since the statistics associated with this disease may vary depending on race and anatomical region. The purpose of this paper was thus to obtain basic data on the clinical statistics of odontogenic cysts in Korea according to the newly revised World Health Organization (WHO) classification system.

\section{MATERIALS AND METHODS}

The subjects of this study were diagnosed and treated for cysts in the jaw at Chonnam National University Hospital from January 2013 to December 2017. A total of 544 patients (mean age: 32.1 years), having been monitored for more than 6 months after surgery with available panoramic radiographs, were reviewed. All patients were examined for types and locations of cysts, bone grafting history, types of graft material, and systemic diseases. This was accomplished by reviewing medical records, clinical examinations, panoramic radiographs, dental CT findings, and biopsy.

Overall, 544 cases, with clinico-radiological diagnosis of a cyst in the oral and maxillofacial region, were selected and treated and the diagnosis was co-related to the eventual histopathological diagnosis. The patients were followed up for at least 6 months (6-12 months). An attempt was made to underline patient and lesion related variables affecting the choice of treatment modality in each case.

Patients were divided into three age groups-pediatric (under 16 years), younger adults (from 17 years to 40 years), and older adults (over 40 years). Depending on the case, surgery was performed under local or general anesthesia and included one of the following treatment modalities: enucleation after marsupialization, enucleation only, and enucleation with bone grafting or resection. The StudentNewman-Keuls method was used for statistical analysis.

\section{RESULTS}

\section{Sex and age distribution}

The mean age at the time of surgery for the maxillofacial 
cystic lesions was 32.1 years (range, 6 to 87 years). Among 544 patients, 352 were male (64.7\%) and 192 were female (35.3\%) with a ratio of $1.83: 1$. By age, the number of males was the greatest in the 41-50-year-old (75 cases, 20.7\%) group and the number of females was the greatest in the 21-30-year-old (46 cases, 24.0\%) group (Table 1).

The types of cysts, mean age and sex of patients, and most affected sites of cysts in the pediatric age group are listed in Table 2. In this group ( $n=54)$, the most common cysts were dentigerous cysts (40.7\%), followed by radicular cysts $(24.1 \%)$, and simple bone cysts $(22.2 \%)$. The mean ages were 11,8 , and 14 years for dentigerous cyst, radicular cyst, and simple bone cyst, respectively. The male to female ratio was $1.35: 1$ in the pediatric age group and 1.89:1 in the adult group. This difference was statistically significant $(p<0.05)$ (Table 2$)$.

Male patients were the most prevalent in the 41-87-yearold (56.5\%) age group. Conversely, the 17-40-year-old group $(50.0 \%)$ had the highest number of female patients (Table 1).

The posterior mandibular area was the most common site affected with 236 cases (42.6\%). The second most common site was the anterior maxillary area with 221 lesions (39.9\%). In 12 cases (2.2\%), simultaneous multiple cystic le-

Table 1. Sex distribution $(\mathrm{n}=544)$

\begin{tabular}{lccc}
\hline Age $(\mathbf{y})$ & Male & Female & Total \\
\hline $6-16$ & $31(8.8)$ & $23(12.0)$ & $54(9.9)$ \\
$17-40$ & $122(34.7)$ & $96(50.0)$ & $218(40.1)$ \\
$41-87$ & $199(56.5)$ & $73(38.0)$ & $272(50.0)$ \\
Total & $352(100)$ & $192(100)$ & $544(100)$
\end{tabular}

Values are presented as number (\%). sions were observed in the maxilla and mandible (Table 3).

The posterior mandibular area was the most common site for a cyst (236 cases, $42.6 \%$ ), followed by the maxillary anterior area (221 cases, 39.9\%), the maxillary posterior area ( 47 cases, $8.5 \%$ ), and the mandibular anterior area (38 cases, 6.9\%). Multiple cystic lesions were observed in 12 patients (2.2\%) (Table 3).

\section{Treatment}

The surgical treatment modalities of the jaw cysts are presented in Table 4. Cyst enucleation and bone graft were performed in 375 cases (68.9\%), followed by enucleation in only 95 cases (17.5\%). Marsupialization alone was performed in 32 patients (5.9\%) and enucleation in 22 cases with bone graft after 6 to 12 months of marsupialization.

Bone graft materials were used as autograft (52.2\%), allograft $(11.0 \%)$, and xenograft (8.9\%) and in 148 cases $(27.2 \%)$, no bone graft was used (Table 5).

Table 2. Histopathologic results of pediatric patients $(n=54)$

\begin{tabular}{lccc}
\hline \multicolumn{1}{c}{ Histopathology } & Male & Female & Total \\
\hline Radicular cyst & $7(22.6)$ & $6(26.12)$ & $13(24.1)$ \\
Dentigerous cyst & $12(38.7)$ & $10(43.5)$ & $22(40.7)$ \\
Nasopalatine duct cyst & $2(6.5)$ & $1(4.3)$ & $3(5.5)$ \\
Odontogenic keratocyst & $1(3.2)$ & $0(0)$ & $1(1.9)$ \\
Simple bone cyst & $7(22.6)$ & $5(21.7)$ & $12(22.2)$ \\
Ameloblastoma & $1(3.2)$ & $0(0)$ & $1(1.9)$ \\
Etc. & $1(3.2)$ & $1(4.3)$ & $2(3.7)$ \\
Total & $31(100)$ & $23(100)$ & $54(100)$ \\
\hline
\end{tabular}

Values are presented as number (\%).

Table 3. Site distribution

\begin{tabular}{|c|c|c|c|c|c|c|c|}
\hline \multirow{2}{*}{ Site } & \multirow{2}{*}{$\begin{array}{c}\text { All patients } \\
(\mathrm{n}=544)\end{array}$} & \multicolumn{2}{|c|}{$\begin{array}{l}\text { Pediatric patient } \\
\qquad(\mathrm{n}=54)\end{array}$} & \multicolumn{2}{|c|}{$\begin{array}{l}\text { Younger adult group } \\
17-40 \text { years }(n=218)\end{array}$} & \multicolumn{2}{|c|}{$\begin{array}{l}\text { Older adult group 41-87 years } \\
\qquad(\mathrm{n}=272)\end{array}$} \\
\hline & & Male & Female & Male & Female & Male & Female \\
\hline Maxillary anterior & $208(38.2)$ & $8(25.8)$ & $6(26.1)$ & $56(45.9)$ & $32(33.3)$ & $85(42.7)$ & $21(28.8)$ \\
\hline Maxillary posterior & $46(8.5)$ & $2(6.5)$ & $2(8.7)$ & $8(6.5)$ & $15(15.6)$ & $12(6.1)$ & $7(9.6)$ \\
\hline Mandibular anterior & $37(6.8)$ & $9(29.0)$ & $4(17.4)$ & $4(3.3)$ & $4(4.2)$ & $10(5.0)$ & $6(8.2)$ \\
\hline Mandibular posterior & $241(44.3)$ & $10(32.2)$ & $10(43.5)$ & $51(41.8)$ & $42(43.8)$ & $90(45.2)$ & $38(52.0)$ \\
\hline Multiple area & $12(2.2)$ & $2(6.5)$ & $1(4.3)$ & $3(2.5)$ & $3(3.1)$ & $2(1.0)$ & $1(1.4)$ \\
\hline Total & $544(100)$ & $31(100)$ & $23(100)$ & $122(100)$ & $96(100)$ & $199(100)$ & $73(100)$ \\
\hline
\end{tabular}

Values are presented as number (\%). 
Yeon-Woo Jeong, et al.

Table 4. Treatment methods $(n=544)$

\begin{tabular}{lc}
\hline \multicolumn{1}{c}{ Treatment method } & Case \\
\hline Enucleation only & $95(17.5)$ \\
Enucleation and bone graft & $375(68.9)$ \\
Marsupialization only & $32(5.9)$ \\
Marsupialization and enucleation with bone graft & $22(4.0)$ \\
Other treatments & $20(3.7)$ \\
$\quad$ (surgical exploration, Cald-Well Luc operation) & \\
Total & $544(100)$ \\
\hline
\end{tabular}

Values are presented as number (\%).

Table 5. Bone graft materials

\begin{tabular}{lc}
\hline Bone graft material & Case \\
\hline Autograft & $284(52.2)$ \\
Allograft & $60(11.0)$ \\
Xenograft & $48(8.9)$ \\
Alloplast or synthetic graft & $4(0.7)$ \\
None & $148(27.2)$ \\
Total & $544(100)$ \\
\hline
\end{tabular}

Values are presented as number (\%).

Table 6. Histopathologic results $(\mathrm{n}=554)$

\begin{tabular}{lccc}
\hline Histopathologic result & Male & Female & Total \\
\hline Radicular cyst & $161(45.7)$ & $98(51.1)$ & $259(47.6)$ \\
Dentigerous cyst & $116(33.0)$ & $44(22.9)$ & $160(29.4)$ \\
Nasopalatine duct cyst & $41(11.6)$ & $16(8.3)$ & $57(10.5)$ \\
Odontogenic keratocyst & $8(2.3)$ & $11(5.7)$ & $19(3.5)$ \\
Simple bone cyst & $11(3.1)$ & $7(3.6)$ & $18(3.3)$ \\
Ameloblastoma & $6(1.7)$ & $3(1.6)$ & $9(1.7)$ \\
Other cysts & $9(2.6)$ & $13(6.8)$ & $22(4.0)$ \\
Total & $352(100)$ & $192(100)$ & $544(100)$ \\
\hline
\end{tabular}

Values are presented as number (\%).

\section{DISCUSSION}

Cystic lesions of the jaws can be either odontogenic or non-odontogenic, and developmental or inflammatory in origin. In the present study, $46.9 \%$ of cysts were developmental while $45.7 \%$ were inflammatory in origin (Table 6). This is in general agreement with the distribution of cyst types found in previously published large studies [9]. However, when looking separately at the pediatric and adult groups (under 16 years and 17-40 years, respectively), a difference in the distribution of radicular cysts, an inflammatory cyst (24.1\% and $53.2 \%$, respectively), and dentiger-
Table 7. Histopathologic results of the 17-40-year-old adult group $(n=218)$

\begin{tabular}{lccc}
\hline \multicolumn{1}{c}{ Histopathology } & Male & Female & Total \\
\hline Radicular cyst & $65(53.3)$ & $51(53.1)$ & $116(53.2)$ \\
Dentigerous cyst & $35(28.7)$ & $18(18.8)$ & $53(24.4)$ \\
Nasopalatine duct cyst & $11(9.0)$ & $11(11.5)$ & $22(10.1)$ \\
Odontogenic keratocyst & $2(1.6)$ & $5(5.2)$ & $7(3.2)$ \\
Simple bone cyst & $3(2.5)$ & $1(1.0)$ & $4(1.8)$ \\
Ameloblastoma & $2(1.6)$ & $2(2.1)$ & $4(1.8)$ \\
Etc. & $4(3.3)$ & $8(8.3)$ & $12(5.5)$ \\
Total & $122(100)$ & $96(100)$ & $218(100)$ \\
\hline
\end{tabular}

Values are presented as number (\%).

Table 8. Histopathologic results of the 41-87-year-old adult group $(\mathrm{n}=272)$

\begin{tabular}{lccc}
\hline \multicolumn{1}{c}{ Histopathology } & Male & Female & Total \\
\hline Radicular cyst & $89(44.7)$ & $41(56.1)$ & $130(47.8)$ \\
Dentigerous cyst & $69(34.7)$ & $16(21.9)$ & $85(31.3)$ \\
Nasopalatine duct cyst & $28(14.1)$ & $4(5.5)$ & $32(11.8)$ \\
Odontogenic cyst & $5(2.5)$ & $6(8.2)$ & $11(4.0)$ \\
Simple bone cyst & $1(0.5)$ & $1(1.4)$ & $2(0.7)$ \\
Ameloblastoma & $3(1.5)$ & $1(1.4)$ & $4(1.5)$ \\
Etc. & $4(2.0)$ & $4(5.5)$ & $8(2.9)$ \\
Total & $199(100)$ & $73(100)$ & $272(100)$ \\
\hline
\end{tabular}

Values are presented as number (\%).

ous cyst, a developmental cyst ( $40.7 \%$ and $24.4 \%$, respectively), was noted. This finding is in agreement with those in earlier reports (Table 2, 7, 8) [10-15].

The difference in prevalence of developmental cysts is most likely related to the fact that during the pediatric period, the jaws are involved in profound developmental processes. These include growth of the maxillofacial skeleton and development of the primary and permanent dentition, all of which can be associated with cyst formation. The difference in distribution of inflammatory cysts may be because radicular cysts arising from primary teeth are very rare [16]. Radicular cysts arising from permanent teeth are also infrequent in pediatric patients, because radicular cysts arise from epithelial residues in the periodontal ligament as a result of inflammation that follows necrosis of the dental pulp. Recently it was shown that erupted permanent teeth in pediatric patients are usually intact.

Usually, clinical manifestation of infection around the cyst is closely related to acute or chronic inflammation at 
the cystic wall. The destruction of the epithelial lining of the cyst wall, regardless of the origin, gives rise to a cyst wall with granulation tissue.

Of the 54 pediatric cases in our series, were male and female, providing a male to female ratio of 1.7. In contrast, of the adult cases, were male and were female, with a male to female ratio of 1.9. This in agreement with the reported distribution of cysts in the general population, where there is a significant difference in the sex-related distribution, with male predominance [17-19].

The greater prevalence in adult males may be because they are more likely to neglect their teeth or are more likely to sustain trauma to their teeth compared to females, all of which can be involved in the etiology underlying cyst formation [16].

For most of the cysts, panoramic radiographs and dental CT were adequate imaging modalities. The dental CT, originally designed for implant dentistry, has proven to be useful in the evaluation of jaw abnormality and pathology. Using this, anatomic structures, such as the mandibular canal, mental foramen, incisive canal, and maxillary sinus, can be seen in cross-section. Dental CT has also been shown to be superior to plain film radiography in demonstrating cystic lesions of the jaws and in evaluating bone regeneration following marsupialization of jaw cysts [20-22]. It also allows planning of the surgical approach with least morbidity to the adjacent anatomic structures.

The treatment objective is restoring the morphology and function of the affected area. There are two basic surgical procedures, namely marsupialization (decompression) and enucleation. Marsupialization, a relatively simple procedure, consists of surgically producing a "window" in the cystic wall to relieve intra-cystic tension. After this, the cystic cavity slowly decreases in size. The cavity is lightly packed with paraffin gauze until the junction between the cystic lining and the oral mucosa has healed. Three to six months later, enucleation is performed [23].

Notable disadvantages of the technique are: (a) it is a two-stage surgical procedure, (b) pathological tissue is left behind and a more sinister pathological process (i.e., squamous cell carcinoma) may be overlooked [24], and (c) in large cystic cavities, it takes a long time for the bone to regenerate.
Cysts of the jaw are commonly found lesions and clinically important pathological entities due to their invasive character. Among them, the odontogenic cyst is capable of destroying surrounding tissues, which may cause absorption or expansion of the jaw, pathological fracture, and facial deformities leading to functional and aesthetic defects. Thus, it is very important to diagnose and treat odontogenic cysts in the early stages. Cysts are classified according to their origins, and most scholars use the WHO classification. This study was also based on the WHO classification system [25,26].

Radiological images of cystic lesions and patient's age were found to be the two most important variables affecting treatment planning, while factors such as size and site of the lesion did not have any major impact on treatment planning.

Age as the most important clinical variable attests to the importance given by operators to the patients' quality of life, while considering the options with respect to recurrence or future treatment $[27,28]$. History of previous surgery, on the other hand, is taken into account by operators and is an indication to treat the lesion aggressively, giving precedence to longevity and prognosis of treatment.

Enucleation was validated as the most suitable modality for almost all cysts, with various adjunctive procedures (as deemed necessary per case). Relatively complicated procedures were chosen more due to the age, clinical presentation, relatively aggressive clinical course, or poorly accessible site of lesions, rather than the histopathological diagnosis, further underlining the need for and relevance of custom-made treatment plans for each patient.

The treatment results were satisfactory in all cases, justifying the choice of treatment modalities, though the study period was inadequate to observe long term recurrence or neoplastic transformations of the lesions [29,30].

Regardless of the type of cyst, the largest number of patients by age group was in their 40s (18.6\%), followed by $20 \mathrm{~s}(17.1 \%)$ and $30 \mathrm{~s}(17.1 \%)$ and then $50 \mathrm{~s}, 10 \mathrm{~s}$, and $60 \mathrm{~s}$. The prevalence of cysts in the 20-40-year-old group was more than half (52.8\%) that in the entire cohort. Therefore, the highest occurrence of cysts in the jaw can be estimated to be somewhere between age groups of $20 \mathrm{~s}$ and $40 \mathrm{~s}$. In the study by Arotiba et al. [31], patients in their 20s had the 
greatest prevalence of cysts (44.4\%). Observed that patients in their 20s had the highest prevalence among the African populations (44\%). The above two studies demonstrate somewhat different results from the data retrieved in this study.

The pathologic distribution shows that the radicular cyst is the most prevalent (47.6\%), followed by dentigerous cyst (29.4\%), nasopalatine duct cyst (10.5\%), and odontogenic keratocyst (3.5\%). The most common cyst in all countries was the radicular cyst, followed by the dentigerous cyst, the odontogenic keratocyst, and the residual cyst. However, the results of this study show that the distribution of the residual cyst and the odontogenic keratocyst were similar, and a study from Spain showed that the distribution of the residual cyst was higher than that of odontogenic keratocyst [6]. These results suggest that the incidence of the odontogenic keratocyst varies according to race and geography.

The most commonly occurring sites for cysts were the posterior mandibular area (42.6\%) and the anterior maxillary area (39.9\%). A possible explanation for why radicular cysts are frequently found in the anterior maxillary area in particular is that the maxillary anterior area is a common site for trauma, which therefore may lead to a radicular cyst with the progression of necrosis [32].

Bone grafts can be used where a bone defect is seen to improve healing of the bone after cyst enucleation. There are several grafting materials available, but fresh autogenous bone graft is known to have the best results. Moreover, the iliac bone is a preferred donor site due to its good accessibility and quality [14].

Based on the clinical and histopathological findings demonstrated in this study, it is essential that cystic lesions be enucleated if there is no fatal damage to the neighboring anatomical structures and bone. Further, more long term follow up of cystic lesions is advised, especially for dentigerous cysts and odontogenic keratocysts.

In this study, the prevalence rate of radicular cyst was higher than that of other types of cysts. Further, the prevalence of cysts was higher in older patients, and the prevalence of radicular cysts was high among older patients, while the prevalence of dentigerous cysts was high among younger patients. Treatment of cysts should be based on complete enucleation and bone grafting should be employed as necessary.

\section{CONFLICTS OF INTEREST}

The authors declare that they have no competing interests.

\section{ORCID}

\author{
Yeon-Woo Jeong \\ https://orcid.org/0000-0003-2318-7202 \\ Byung-Hun Kang \\ https://orcid.org/0000-0001-5037-3225 \\ Min-Jung Park \\ https://orcid.org/0000-0001-8029-8799 \\ Song-Jay Choi \\ https://orcid.org/0000-0003-2120-9498 \\ Hong-Ju Park \\ https://orcid.org/0000-0001-7652-5397 \\ Hee-Kyun Oh \\ https://orcid.org/0000-0003-0391-7095 \\ Min-Suk Kook \\ https://orcid.org/0000-0002-8053-8534
}

\section{REFERENCES}

1. Andersson L, Kahnberg KE, Pogrel MA. Oral and maxillofacial surgery. Chichester: Wiley-Blackwell; 2010;621.

2. Demirkol M, Ege B, Yanik S, Aras MH, Ay S. Clinicopathological study of jaw cysts in southeast region of Turkey. Eur J Dent 2014;8:107-111. doi: 10.4103/1305-7456.

3. Montevecchi M, Checchi V, Bonetti GA. Management of a deeply impacted mandibular third molar and associated large dentigerous cyst to avoid nerve injury and improve periodontal healing: case report. J Can Dent Assoc 2012;78:c59.

4. Swantek JJ, Reyes MI, Grannum RI, Ogle OE. A technique for long term decompression of large mandibular cysts. J Oral Maxillofac Surg 2012;70:856-859. doi: 10.1016/ j.joms.2011.03.029.

5. Strickland M, Singer SR, Rinaggio J, Kim IH, Mupparapu M. Large, expansile odontogenic cyst with bilateral maxillary sinus involvement. N Y State Dent J 2013;79:38-40.

6. Nuñez-Urrutia S, Figueiredo R, Gay-Escoda C. Retrospective clinicopathological study of 418 odontogenic cysts. 
Med Oral Patol Oral Cir Bucal 2010;15:e767-e773. doi: 10.4317/medoral.15.e767.

7. Partsch, C. Uber kiefercysten. Deutsche Monatsschrift Fur Zahnheilkunde. 1892;10:271.

8. Partsch, C. Zur behandlung der kieferzysten. Deutsche Monatsschrift Fur Zahnheilkunde. 1910;28:252.

9. Ochsenius G, Escobar E, Godoy L, Peñafiel C. Odontogenic cysts: analysis of 2,944 cases in Chile. Med Oral Patol Oral Cir Bucal 2007;12:E85-E91.

10. Radden BG, Reade PC. Odontogenic cysts. A review and a clinicopathological study of 368 odontogenic cysts. Aust Dent J 1973;18:218-225. doi: 10.1111/j.1834-7819.1973. tb03470.x.

11. Pechalova PF, Bakardjiev AG, Beltcheva AB. Jaw cysts at children and adolescence: a single-center retrospective study of 152 cases in southern Bulgaria. Med Oral Patol Oral Cir Bucal 2011;16:e767-e771. doi: 10.4317/medoral.16849.

12. Kreidler JF, Raubenheimer EJ, van Heerden WF. A retrospective analysis of 367 cystic lesions of the jaw--the Ulm experience. J Craniomaxillofac Surg 1993;21:339-341. doi: 10.1016/S1010-5182(05)80494-9.

13. Daley TD, Wysocki GP, Pringle GA. Relative incidence of odontogenic tumors and oral and jaw cysts in a Canadian population. Oral Surg Oral Med Oral Pathol 1994;77:276280. doi: 10.1016/0030-4220(94)90299-2.

14. Jones AV, Craig GT, Franklin CD. Range and demographics of odontogenic cysts diagnosed in a UK population over a 30-year period. J Oral Pathol Med 2006;35:500-507. doi: 10.1111/j.1600-0714.2006.00455.x.

15. Iatrou I, Theologie-Lygidakis N, Leventis M. Intraosseous cystic lesions of the jaws in children: a retrospective analysis of 47 consecutive cases. Oral Surg Oral Med Oral Pathol Oral Radiol Endod 2009;107:485-492. doi: 10.1016/ j.tripleo.2008.10.004.

16. Killey HC, Kay LW. An analysis of 471 benign cystic lesions of the jaws. Int Surg 1966;46:540-545.

17. Meningaud JP, Oprean N, Pitak-Arnnop P, Bertrand JC. Odontogenic cysts: a clinical study of 695 cases. J Oral Sci 2006;48:59-62. doi: 10.2334/josnusd.48.59.

18. Jones AV, Franklin CD. An analysis of oral and maxillofacial pathology found in children over a 30-year period. Int J Paediatr Dent 2006;16:19-30. doi: 10.1111/j.1365263X.2006.00683.x.

19. Tortorici S, Amodio E, Massenti MF, Buzzanca ML, Burruano F, Vitale F. Prevalence and distribution of odontogenic cysts in Sicily: 1986-2005. J Oral Sci 2008;50:15-18. doi: 10.2334/josnusd.50.15.

20. Bodner L, Woldenberg Y, Bar-Ziv J. Radiographic features of large cystic lesions of the jaws in children. Pediatr Radiol 2003;33:3-6. doi: 10.1007/s00247-002-0816-2.

21. Hisatomi M, Asaumi J, Konouchi H, Shigehara H, Yanagi Y, Kishi K. MR imaging of epithelial cysts of the oral and maxillofacial region. Eur J Radiol 2003;48:178-182. doi: 10.1016/S0720-048X(02)00218-8.

22. Krennmair G, Lenglinger F. Imaging of mandibular cysts with a dental computed tomography software program. Int J Oral Maxillofac Surg 1995;24(1 Pt 1):48-52. doi: 10.1016/ S0901-5027(05)80856-2.

23. Bodner L, Bar-Ziv J. Characteristics of bone formation following marsupialization of jaw cysts. Dentomaxillofac Radiol 1998;27:166-171. doi: 10.1038/sj/dmfr/4600344.

24. Bodner L, Manor E, Shear M, van der Waal I. Primary intraosseous squamous cell carcinoma arising in an odontogenic cyst: a clinicopathologic analysis of 116 reported cases. J Oral Pathol Med 2011;40:733-738. doi: 10.1111/ j.1600-0714.2011.01058.x.

25. Soluk-Tekkeşin M, Wright JM. The World Health Organization classification of odontogenic lesions: a summary of the changes of the 2017 (4th) edition. Turk Patoloji Derg 2018;34(1). doi: 10.5146/tipath.2017.01410.

26. El-Naggar AK, Chan JKC, Grandis JR, Takata T, Slootweg PJ. WHO classification of head and neck tumours. 4th ed. Geneva: World Health Organization; 2017.

27. Martínez-Pérez D, Varela-Morales M. Conservative treatment of dentigerous cysts in children: a report of 4 cases. J Oral Maxillofac Surg 2001;59:331-333. doi: 10.1053/ joms.2001.21006.

28. Young CW, Pogrel MA, Schmidt BL. Quality of life in patients undergoing segmental mandibular resection and staged reconstruction with nonvascularized bone grafts. J Oral Maxillofac Surg 2007;65:706-712. doi: 10.1016/ j.joms.2006.05.064.

29. Stoelinga PJ. Long-term follow-up on keratocysts treated according to a defined protocol. Int J Oral Maxillofac Surg 2001;30:14-25. doi: 10.1054/ijom.2000.0027.

30. Chaisuparat R, Coletti D, Kolokythas A, Ord RA, Nikitakis NG. Primary intraosseous odontogenic carcinoma arising in an odontogenic cyst or de novo: a clinicopathologic study of six new cases. Oral Surg Oral Med Oral Pathol Oral Radiol Endod 2006;101:194-200. doi: 10.1016/ j.tripleo.2005.03.037.

31. Arotiba JT, Lawoyin JO, Obiechina AE. Pattern of occurrence of odontogenic cysts in Nigerians. East Afr Med J 1998;75:664-666.

32. Rim JS, Jang HS, Son HM, Nam YW. Clinical study of cyst in the jaws. J Korean Assoc Oral Maxillofac Surg 2000; 26:293-296. 